\title{
GEOQUIMICA DE ELEMENTOS TERRAS RARAS EM ALLANITAS E TITANITAS DE ROCHAS GRANÍTICAS DE MORUNGABA (SP) E IMPLICAÇÕES PRELIMINARES
}

\author{
S.R.F.Vlach
}

Agradavam ao Prof. Mario Figueiredo as discussões sobre a geoquímica das rochas graníticas e associadas, com destaque para os elementos terras raras (ETR) e o seu significado para a discriminação da tipologia e para a evolução do magmatismo granítico de uma forma geral. Parece oportuno então se apresentar e discutir neste memorial dados de quimismo mineral para allanitas e titanitas de rochas graníticas. Estes minerais estão entre os que contêm as maiores concentrações em elementos terras raras em granitóides meta-aluminosos a moderadamente peraluminosos, e, portanto, o seu quimismo é fundamental para a compreensão da variabilidade dos ETR nestas rochas e para quaisquer modelagens de evolução magmática.

Pares coexistentes de allanitas-titanitas em amostras representativas do Complexo Ouro Verde e dos Plútons Jaguari, Meridional e Oriental do magmatismo Morungaba (Vlach, 1993) foram selecionados para estudo. Nas amostras consideradas, estes minerais aparecem com dimensões submilimétricas a milimétricas e são em geral idiomórficos, mais ou menos zonados ao microscópio óptico; cada qual soma quantidades modais sempre inferiores a $1 \%$. Em geral, a allanita é mais precoce, a sua cristalização iniciando pouco antes do aparecimento da apatita e do zircão. A titanita é algo posterior e a sua formação se inicia a partir de reações peritéticas entre ilmenita ou ilmenita+hornblenda e líquido magmático.

As análises foram realizadas na microssonda JEOL JXA-8600S, automatizada com o sistema TRACOR-NORAN TN-5600 do Departamento de Mineralogia e Petrologia do Instituto de Geociências da USP, sob feixe eletrônico com diâmetro de $10 \mu, 20$ kVa de aceleração e $100 \mathrm{nA}$ de corrente. Varreduras detalhadas de comprimento de onda foram efetuadas para a determinação dos elementos acima do limite de identificação e posicionamento adequado para leituras da radiação de fundo; entre os ETR, La, Ce, Pr, Nd, Sm, Gd e Dy, além de $\mathrm{Y}$, foram passiveis de determinação quantitativa na maioria das amostras. Análises pontuais completas em regiões de núcleo e de borda de cristais selecionados foram acompanhadas de perfis semi-quantitativos núcleo $=>$ borda para os elementos que apresentaram maior variabilidade. Os padrões utilizados são referidos internamente no laboratório. As correções para os efeitos de matriz seguiram o procedimento PROZA disponivel no sistema TN-5600.

A maioria das allanitas estudadas, mesmo quando de aparência muito límpida ao microscópio, encontra-se variavelmente metamictizada, fato refletido por valores relativamente baixos para os totais analíticos (90-95\% em peso de óxidos); de fato, apenas alguns núcleos cristalinos, em especial aqueles com teores mais baixos em $\mathrm{ThO}_{2}$, encontram-se preservados. Deve ser destacado que nas análises com totais superiores a $92-94 \%$, em cristais com alteração carbonática ausente ou muito incipiente, não foram observadas evidências claras de alteração

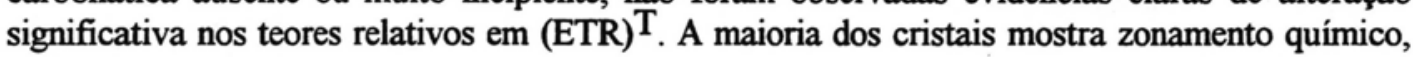

DMP, Instituto de Geociências, Universidade de São Paulo. 
ora mais regular, ora complexo e de tipo oscilatório, com tendências mais ou menos marcadas de diminuição nos teores de (ETR)T dos núcleos para as bordas, paralelizadas pelo aumento de $\mathrm{Na}$, $\mathrm{Sr}$ e $\mathrm{Th}$; os valores de (ETR) $\mathrm{T}_{2} \mathrm{O}_{3}$ se situam entre $17 \%$ e $25 \%$ em peso e são em média mais elevados nas allanitas das rochas mais máficas do Complexo Ouro Verde e do Plúton Jaguari (amostras A-1208 e A-281, respectivamente), as quais são também relativamente mais ricas nas terras raras médias e pesadas.

As titanitas mostram, analogamente, padrões diversificados de zonamento químico, com tendência melhor marcada de diminuição dos teores nas terras raras dos núcleos para as margens dos cristais, paralelizada por $\mathrm{Nb}$ e $\mathrm{Zr}$ e contraposta por $\mathrm{Al}$. Nas amostras consideradas, os teores em (ETR) $\mathrm{T}_{2} \mathrm{O}_{3}$ estão entre $3,5 \%$ e $0,5 \%$.

As principais variações dos elementos terras raras, incluindo $\mathrm{Y}$, são ilustradas em diagramas parciais normalizados pelos teores condríticos (Boynton, 1984) e pelos teores em rocha total (Vlach, 1993) na Figura 1. Por simplicidade, estão representadas nesta Figura apenas os resultados obtidos para os núcleos cristalinos dos pares allanita-titanita, os quais reafirmam, por um lado, a preferência relativa dos ETRL pela allanita e dos ETRP pela titanita, e, por outro, a importância destes dois minerais como depositários principais dos ETR nas amostras estudadas, apresentando concentrações entre 10 e 1300 vezes superiores às da rocha hospedeira. De fato, avaliações modais e normativas das fases minerais mais ricas em ETR (hornblenda, allanita, titanita, apatita e zircão) mostram que mais de $85 \%$ em peso destes elementos nos granitóides meta-aluminosos a moderadamente peraluminosos de Morungaba estão concentrados nestes dois minerais.
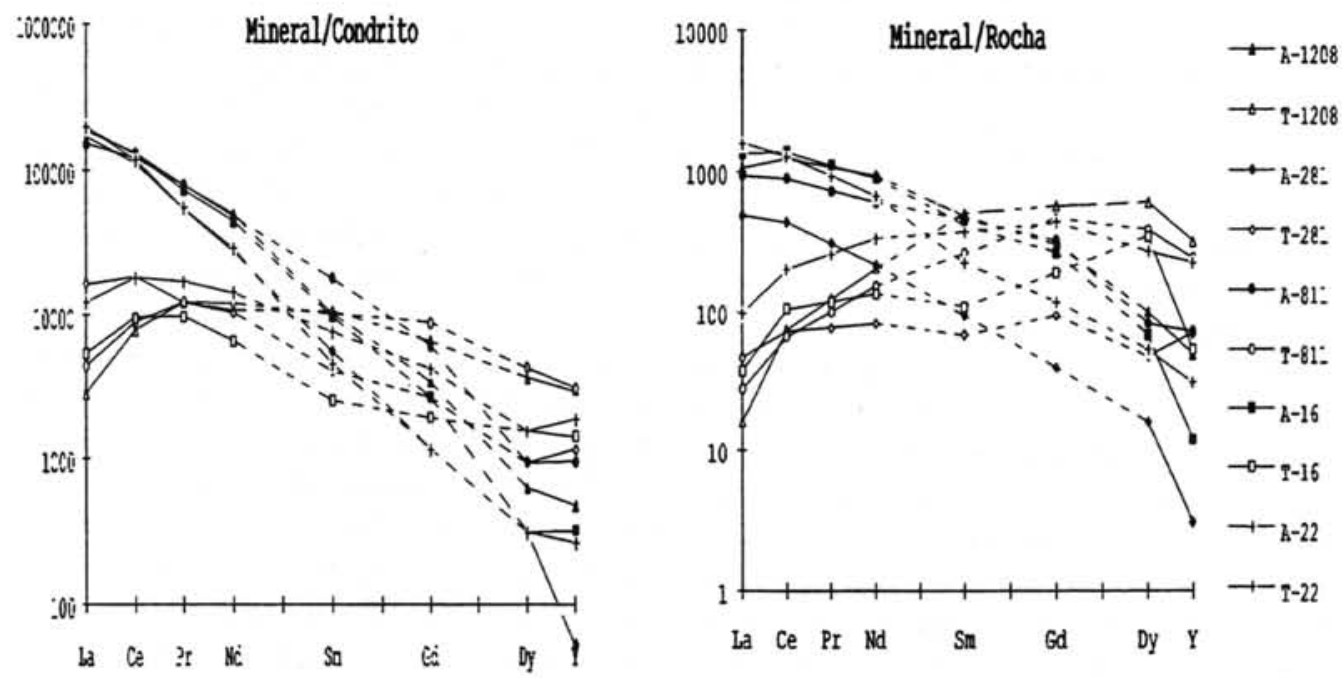

Figura 1 - Diagramas parciais para elementos terras raras, incluindo $\mathrm{Y}$, normalizados pelo condrito de Boynton (1984), à esquerda, e pela rocha hospedeira, à direita. Números na legenda identificam amostras 1208 (Complexo Ouro Verde), 281 e 811 (Plúton Jaguari), 16 (Plúton Oriental), 22 (Plúton Meridional). Letras A e T identificam allanitas e titanitas, respectivamente. 
A concentração dos ETR nas allanitas e nas titanitas das rochas estudadas, a exemplo de outras ocorrências graníticas, depende do índice de diferenciação, da paragênese e da seqüência de cristalização. Destacam-se, por um lado, os teores maiores e menores de terras raras nas titanitas e allanitas, respectivamente, das rochas relativamente mais félsicas dos Plútons Meridional e Oriental (A-16, A-22) quando comparados aos das demais amostras, e, por outro, a importância relativamente menor das titanitas e allanitas como concentradores dos ETR na amostra A-281 quando comparadas com o caso da amostra A-1208, ambas com indice de diferenciação parecido. Este último caso é explicado pela presença de hornblenda, mineral que pode concentrar teores significativos de ETR (e.g., Sawka, 1988), de cristalização precoce em relação à allanita e titanita, na amostra A-281, e a sua ausência em A-1208.

As variações composicionais observadas nas amostras estudadas, em especial aquelas associadas ao zonamento oscilatório, quando estudadas à luz do quimismo de rocha total, são compatíveis com modelos evolutivos embasados em mecanismos simples de cristalização fracionada a partir de volumes discretos de magmas, com envolvimento de mistura e/ou desmistura entre líquidos magmáticos e frações previamente cristalizadas. Por outro lado, a combinação dos padrões minerais obtidos com os de rocha total apontam para a proporcionalidade entre as quantidades fracionadas de minerais acessórios e os respectivos coeficientes de partição para os elementos considerados (v. também Vlach, 1993).

\section{Referências Bibliográficas}

BOYNTON, W.V. (1984) Cosmochemistry of the rare earth elements: meteorite studies. In: HENDERSON, P. (Ed.) Rare earth element geochemistry. Amsterdan, Elsevier, p.63114.

SAWKA, W.N. (1988) REE and trace element variations in accessory minerals and hornblende from the strongly zoned McMurry Meadows pluton, California. Transactions of the Royal Society of Edinburgh: Earth Sciences, v.79, n.2-3, p.157-168.

VLACH, S.R.F. (1993) Geologia e Petrologia dos granitóides de Morungaba, SP. São Paulo, 414p. (Tese - Doutorado) - Instituto de Geociências, Universidade de São Paulo. 